\title{
Form Error Models of the NIST Algorithm Testing System
}

Mary Elizabeth A. Algeo Theodore H. Hopp

U.S. DEPARTMENT OF COMMERCE

Technology Administration

National Institute of Standards

and Technology

Manufacturing Engineering Laboratory

Factory Automation Systems Division

Machine Intelligence Group

Gaithersburg, MD 20899-0001

Sponsored by

Navy Manufacturing Technology Program

and

National Institute of Standards and Technology

U.S. DEPARTMENT OF COMMERCE

Rockwell A. Schnabel, Acting Secretary

NATIONAL INSTITUTE OF STANDARDS

AND TECHNOLOGY

John W. Lyons, Director

100

.456 



\title{
NISTIR 4740
}

\section{Form Error Models of the NIST Algorithm Testing System}

Mary Elizabeth A. Algeo

Theodore H. Hopp

\author{
U.S. DEPARTMENT OF COMMERCE \\ Technology Administration \\ National Institute of Standards \\ and Technology \\ Manufacturing Engineering Laboratory \\ Factory Automation Systems Division \\ Machine Intelligence Group \\ Gaithersburg, MD 20899
}

Sponsored by

Navy Manufacturing Technology Program

and

National Institute of Standards and Technology

January 1992

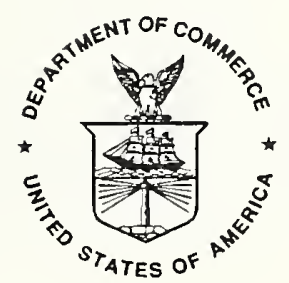

U.S. DEPARTMENT OF COMMERCE

Rockwell A. Schnabel, Acting Secretary

NATIONAL INSTITUTE OF STANDARDS

AND TECHNOLOGY

John W. Lyons, Director 
$$
\text { . }
$$ 


\title{
FORM ERROR MODELS OF THE NIST ALGORITHM TESTING SYSTEM
}

\author{
Mary Elizabeth A. Algeo and Theodore H. Hopp \\ National Institute of Standards and Technology \\ Gaithersburg, MD 20899-0001
}

The NIST Algorithm Testing System (or ATS) is a software package for testing the performance of geometric fitting software used in metrology systems ${ }^{1}$. One of the functions of the ATS is to generate test data simulating point measurements taken from manufactured parts. Data sets are generated by evaluating, according to user-specified sampling plans, models of parts with simulated form errors. The ATS also provides a simple model of point measurement errors. The purpose of this report is to document the form error models used in the ATS.

The ATS uses a parametric representation of geometry. A form error is simulated by computing, from the parametric coordinates of a point on an ideal geometric element, the cartesian coordinates of a form error vector at that point. This error vector is added to the ideal point vector to generate a point on a simulated surface with form error. A simulated measurement point is finally generated by adding a random measurement error vector. In summary, a point generated by the ATS data generator is of the form:

$$
\mathbf{p}(u, v)=\mathbf{p}_{0}(u, v)+\Delta \mathbf{p}_{\mathrm{F}}(u, v)+\Delta \mathbf{p}_{\mathrm{M}}
$$

where $(u, v)$ are the parametric coordinates of the point (according to the sampling plan), $\mathbf{p}_{0}(u, v)$ is the point on the ideal geometry, $\Delta \mathrm{p}_{\mathrm{F}}(u, v)$ is the form error, and $\Delta \mathrm{p}_{\mathrm{M}}$ is the measurement error at that point. (The above description applies to surface geometries. Curve geometries are similar, but only use a single evaluation parameter.)

The ATS simulates different kinds of form errors for different ideal geometries. However, a random form error is supported for all curve and surface types. This consists of a displacement perpendicular to the ideal geometry by some random distance. Random form errors are not reproducible: evaluating the same surface at the same parametric coordinates will produce a different point. For other than random form errors, the ideal geometries and corresponding form error types are as follows:

\begin{tabular}{|c|c|c|}
\hline Geometry & Form Error & Description \\
\hline \multirow[t]{3}{*}{ Line } & Sine & $\begin{array}{l}\text { A sinusoidal oscillation perpendicular to a line. } \\
\text { The oscillation takes place in a plane determined } \\
\text { by the ideal line definition. }\end{array}$ \\
\hline & Step & $\begin{array}{l}\text { A discontinuity in a line. After the step, the line } \\
\text { continues in the same direction, but displaced from } \\
\text { the original line. The displacement is in a plane } \\
\text { determined by the ideal line definition. }\end{array}$ \\
\hline & Bend & $\begin{array}{l}\text { A change in direction of a line. At the bend, the } \\
\text { line is continuous, but the direction of the line is } \\
\text { discontinuous The new line lies in a plane deter- } \\
\text { mined by the ideal line definition. }\end{array}$ \\
\hline
\end{tabular}

\footnotetext{
${ }^{1}$ An overview report on the ATS is in preparation.
} 


\begin{tabular}{lll} 
Geometry & Form Error & Description \\
\hline Circle & Sine & $\begin{array}{l}\text { A sinusoidal oscillation perpendicular to a circle, in } \\
\text { the plane of the circle. To keep the curve simple, } \\
\text { the amplitude of the oscillation should be less than } \\
\text { the radius of the circle. } \\
\text { A discontinuity in the radius of the circle between } \\
\text { two polar angles. }\end{array}$ \\
\hline Plane & Sine & $\begin{array}{l}\text { A two-dimensional sinusoidal oscillation about a } \\
\text { plane. The oscillation is perpendicular to the } \\
\text { plane. }\end{array}$ \\
& Step & $\begin{array}{l}\text { A discontinuity in a plane at a line in the plane. } \\
\text { One one side of the line of discontinuity, the plane } \\
\text { is displaced, but parallel to, the plane on the other } \\
\text { side. }\end{array}$ \\
& Bend & $\begin{array}{l}\text { A sharp bend or crease in a plane along a line. On } \\
\text { both sides of the line, the plane has local ortho- } \\
\text { gonal coordinate systems. The normals are differ- } \\
\text { ent. }\end{array}$ \\
\hline Sphere & Sine & $\begin{array}{l}\text { A two-dimensional sinusoidal oscillation perpendic- } \\
\text { ular to a sphere. To keep the surface simple, the } \\
\text { maximum amplitude of the oscillation should be } \\
\text { less than the radius of the sphere. }\end{array}$ \\
\hline
\end{tabular}

$\begin{array}{ll}\text { Cylinder or Axial sine } & \text { A sinusoidal oscillation of the axis. The oscillation } \\ \text { Cone } & \text { takes place in a plane containing the ideal axis. } \\ \text { (Refer to the sine error for a line.) }\end{array}$

Radial sine A sinusoidal oscillation of the radius at each cross section perpendicular to the axis. (Refer to the sine error for a circle.)

Axial radius sine A sinusoidal oscillation of the radius along the axis.
Axial step
Radial step
A discontinuity of the axis. (Refer to the step error for a line.)
A discontinuity in the radius at each cross section perpendicular to the axis. (Refer to the step error for a circle.)

Axial radius step A discontinuity in the radius along the axis.

The tables on the following pages summarize the form error models used in the ATS. There is one table for each type of ideal geometry supported by the ATS. Each table presents the types of form errors supported for that geometry, the parameters that define each error type, a name for each form error parameter, and an equation for the error vector as a function of parametric coordinates of points on the ideal surface. 
Throughout these tables, the following special functions are used:

- The unit step function:

$$
S(x)= \begin{cases}0 & x<0 \\ 1 & x \geq 0\end{cases}
$$

- The positive ramp function:

$$
\mathrm{T}(x)= \begin{cases}0 & x \leq 0 \\ x & x>0\end{cases}
$$

- The function $U(\alpha, \beta)$ : a uniformly-distributed random variate in the range $[\alpha, \beta]$.

The tables also assume that each geometry has a local cartesian coordinate system, which is used to evaluate each form error vector. The local coordinate system is described briefly at the end of each table. The geometry of the ATS is based on STEP ${ }^{2}$. More complete information about geometry representations used in the ATS is in preparation.

2 STEP is an acronym for an emerging international standard, the Standard for the Exchange of Product Model Data. The geometry of the ATS is based on Part 42 of STEP, specifically, the following document of ISO/TC 184/SC 4: Product Data Representation and Exchange-Part 42: Integrated Resources: Geometric and Topological Representation, ISO Committee Draft 10303-42, June 21, 1991. 
LINES

\begin{tabular}{|c|c|c|c|}
\hline Error & Parameter & Parameter name & Equation \\
\hline \multirow{3}{*}{ Sine } & $A$ & amplitude & \multirow{3}{*}{$A \sin (f \hat{u}+p) \mathbf{n}_{\perp}$} \\
\hline & $f$ & frequency & \\
\hline & $p$ & phase & \\
\hline \multirow{2}{*}{ Step } & $A$ & amplitude & \multirow[t]{2}{*}{$A \mathrm{~S}\left(u-u_{0}\right) \mathbf{n}_{\perp}$} \\
\hline & $u_{0}$ & location & \\
\hline \multirow{2}{*}{ Bend } & $\mathrm{n}_{1}$ & new direction & \multirow[t]{2}{*}{$\mathrm{T}\left(u-u_{0}\right)\left(\mathbf{n}_{1}-\mathbf{n}\right)$} \\
\hline & $u_{0}$ & location & \\
\hline Random & $A$ & amplitude & $\mathrm{U}(-A, A) \mathbf{n}_{\perp}$ \\
\hline
\end{tabular}

The local coordinate system consists of $\mathbf{n}$, the direction of the line.

In the above equations,

$$
\mathbf{n}_{\perp}=\frac{\mathbf{n}^{\prime} \times \mathbf{n}}{\left|\mathbf{n}^{\prime} \times \mathbf{n}\right|}, \text { where } \mathbf{n}^{\prime}= \begin{cases}\mathbf{n} \times \mathbf{x} & |\mathbf{n} \cdot \mathbf{z}|>0.9 \\ \mathbf{n} \times \mathbf{z} & |\mathbf{n} \cdot \mathbf{z}| \leq 0.9\end{cases}
$$

is the unit direction perpendicular to $\mathbf{n}$ closest to the $+\mathbf{z}$ axis (or $+\mathbf{x}$ axis if $\mathbf{n}$ is close to $\mathbf{z}$ ). Also, if the line is parameterized from $u_{\min }$ to $u_{\max }$,

$$
\hat{u}=2 \pi \frac{u-u_{\text {min }}}{u_{\text {max }}-u_{\text {min }}}
$$

is the normalized coordinate of the point in the line segment being modeled. (In other words, the frequency $f$ indicates the total number of wavelengths of form error oscillation in the line segment.) 
CIRCLES

\begin{tabular}{|c|c|c|c|}
\hline Error & Parameter & Parameter name & Equation \\
\hline \multirow{3}{*}{ Sine } & $A$ & amplitude & \multirow{2}{*}{$A \sin (f u+p) \mathbf{n}(u)$} \\
\cline { 2 - 3 } & $f$ & frequency & \\
\cline { 2 - 3 } & $p$ & phase & \\
\hline \hline \multirow{3}{*}{ Step } & $A$ & amplitude & \multirow{2}{*}{$A\left(\mathrm{~S}\left(u-u_{0}\right)-\mathrm{S}\left(u-u_{1}\right)\right) \mathbf{n}(u)$} \\
\cline { 2 - 3 } & $u_{0}$ & start angle & \\
\cline { 2 - 3 } & $u_{1}$ & end angle & $\mathrm{U}(-A, A) \mathbf{n}(u)$ \\
\hline \hline Random & $A$ & amplitude & \\
\hline
\end{tabular}

The local coordinate system consists of $\mathbf{n}_{1}$ and $\mathbf{n}_{2}$, two perpendicular directions in the plane of the circle.

In the table,

$$
\mathbf{n}(u)=(\cos u) \mathbf{n}_{1}+(\sin u) \mathbf{n}_{2}
$$

is the unit direction, away from the center, perpendicular to the circle at $u$. 
PLANES

\begin{tabular}{|c|c|c|c|}
\hline Error & Parameter & Parameter name & Equation \\
\hline \multirow{6}{*}{ Sine } & $A_{u}$ & amplitude in $u$ & \multirow{6}{*}{$\begin{array}{l}{\left[A_{u} \sin \left(f_{u} \hat{u}+p_{u}\right)\right.} \\
\left.\quad+A_{v} \sin \left(f_{v} \hat{v}+p_{v}\right)\right] \mathbf{n}_{3}\end{array}$} \\
\hline & $f_{u}$ & frequency in $u$ & \\
\hline & $p_{u}$ & phase in $u$ & \\
\hline & $A_{v}$ & amplitude in $v$ & \\
\hline & $f_{v}$ & frequency in $v$ & \\
\hline & $p_{\nu}$ & phase in $v$ & \\
\hline \multirow{3}{*}{ Step } & $d$ & amplitude & \multirow{3}{*}{$A \mathrm{~S}(u \sin \alpha-v \cos \alpha-d) \mathbf{n}_{3}$} \\
\hline & $d$ & distance & \\
\hline & $\alpha$ & orientation & \\
\hline \multirow{3}{*}{ Bend } & $\mathbf{n}_{3}^{\prime}$ & new normal & \multirow{3}{*}{$\begin{array}{r}\mathrm{T}(u \sin \alpha-v \cos \alpha-d) \\
\quad\left|\mathbf{n}_{3}-\mathbf{n}_{3}^{\prime}\right| \frac{\left(\mathbf{n}_{3}+\mathbf{n}_{3}^{\prime}\right)}{\left|\mathbf{n}_{3}+\mathbf{n}_{3}^{\prime}\right|}\end{array}$} \\
\hline & $d$ & distance & \\
\hline & $\alpha$ & orientation & \\
\hline Random & $A$ & amplitude & $\mathrm{U}(-A, A) \mathbf{n}_{3}$ \\
\hline
\end{tabular}

The local coordinate system consists of $\mathbf{n}_{1}, \mathbf{n}_{2}$, and $\mathbf{n}_{3}$, three mutually perpendicular unit vectors, with $\mathbf{n}_{3}$ perpendicular to the plane.

Also, if the plane is parameterized from $u_{\min }$ to $u_{\max }$ in $u$, and similarly for $v$,

$$
\begin{aligned}
& \hat{u}=2 \pi \frac{u-u_{\text {min }}}{u_{\text {max }}-u_{\text {min }}} \\
& \hat{v}=2 \pi \frac{v-v_{\text {min }}}{v_{\text {max }}-v_{\text {min }}}
\end{aligned}
$$

are the normalized coordinates of the point within the planar patch being modeled. (In other words, the frequencies $f_{u}$ and $f_{v}$ indicate the total number of wavelengths of form error oscillation in the $u$ and $v$ extents.) 
SPHERES

\begin{tabular}{|c|c|c|c|}
\hline Error & Parameter & Parameter name & Equation \\
\hline \multirow{6}{*}{ Sine } & $A_{u}$ & amplitude in $u$ & \multirow{6}{*}{$\begin{array}{l}{\left[A_{u} \sin \left(f_{u} u+p_{u}\right)\right.} \\
\left.\quad+A_{v} \sin \left(f_{v} v+p_{v}\right)\right] \mathbf{n}(u, v)\end{array}$} \\
\hline & $f_{u}$ & frequency in $u$ & \\
\hline & $p_{u}$ & phase in $u$ & \\
\hline & $A_{\nu}$ & amplitude in $v$ & \\
\hline & $f_{v}$ & frequency in $v$ & \\
\hline & $p_{v}$ & phase in $v$ & \\
\hline Random & $A$ & amplitude & $\mathrm{U}(-A, A) \mathbf{n}(u, v)$ \\
\hline
\end{tabular}

The local coordinate system consists of $\mathbf{n}_{1}, \mathbf{n}_{2}$, and $\mathbf{n}_{3}$, three mutually perpendicular unit vectors.

In the above equations:

$$
\mathbf{n}(u, v)=(\cos u)(\sin v) \mathbf{n}_{1}+(\sin u)(\sin v) \mathbf{n}_{2}+(\cos v) \mathbf{n}_{3}
$$

is the unit direction, away from the center, perpendicular to the sphere at $(u, v)$. 
CYLINDERS and CONES

\begin{tabular}{|c|c|c|c|}
\hline Error & Parameter & Parameter name & Equation \\
\hline \multirow{4}{*}{ Axial Sine } & $A$ & amplitude & \multirow{4}{*}{$A \sin (f \hat{v}+p) \mathbf{n}\left(u_{0}\right)$} \\
\hline & $f$ & frequency & \\
\hline & $p$ & phase & \\
\hline & $u_{0}$ & reference angle & \\
\hline \multirow{3}{*}{ Radial Sine } & $A$ & amplitude & \multirow{3}{*}{$A \sin (f u+p) \mathbf{n}(u)$} \\
\hline & $f$ & frequency & \\
\hline & $p$ & phase & \\
\hline \multirow{3}{*}{$\begin{array}{l}\text { Axial Radius } \\
\text { Sine }\end{array}$} & $A$ & amplitude & \multirow{3}{*}{$A \sin (f \hat{v}+p) \mathbf{n}(u)$} \\
\hline & $f$ & frequency & \\
\hline & $p$ & phase & \\
\hline \multirow{3}{*}{ Axial Step } & $A$ & amplitude & \multirow{3}{*}{$A \mathrm{~S}\left(v-v_{0}\right) \mathbf{n}\left(u_{0}\right)$} \\
\hline & $v_{0}$ & location & \\
\hline & $u_{0}$ & reference angle & \\
\hline \multirow{3}{*}{ Radial Step } & $A$ & amplitude & \multirow{3}{*}{$A\left(\mathrm{~S}\left(u-u_{0}\right)-\mathrm{S}\left(u-u_{1}\right)\right) \mathbf{n}(u)$} \\
\hline & $u_{0}$ & start angle & \\
\hline & $u_{0}$ & end angle & \\
\hline \multirow{2}{*}{$\begin{array}{l}\text { Axial Radius } \\
\text { Step }\end{array}$} & $A$ & amplitude & \multirow[t]{2}{*}{$A S\left(v-v_{0}\right) \mathbf{n}(u)$} \\
\hline & $v_{0}$ & location & \\
\hline Random & $A$ & amplitude & $\mathrm{U}(-A, A) \mathbf{n}(u)$ \\
\hline
\end{tabular}

The local coordinate system consists of $\mathbf{n}_{1}, \mathbf{n}_{2}$, and $\mathbf{n}_{3}$, three mutually perpendicular unit vectors, with $\mathbf{n}_{3}$ directed along the axis of the cylinder or cone.

In the above equations,

$$
\mathbf{n}(u)=(\cos u) \mathbf{n}_{1}+(\sin u) \mathbf{n}_{2}
$$

is the unit direction, away from the axis, perpendicular to the axis at $u$ (for all $v$ ). Note that, in the case of a cone, the form error is not perpendicular to the surface. 
Also, if the cone is parameterized from $v_{\min }$ to $v_{\max }$ in $v$ (axially),

$$
\hat{v}=2 \pi \frac{v-v_{\min }}{v_{\max }-v_{\min }}
$$

is the normalized $v$ coordinate of the point within the axial segment being modeled. (In other words, the frequency $f$ indicates the total number of wavelengths of form error oscillation along the axis.) 



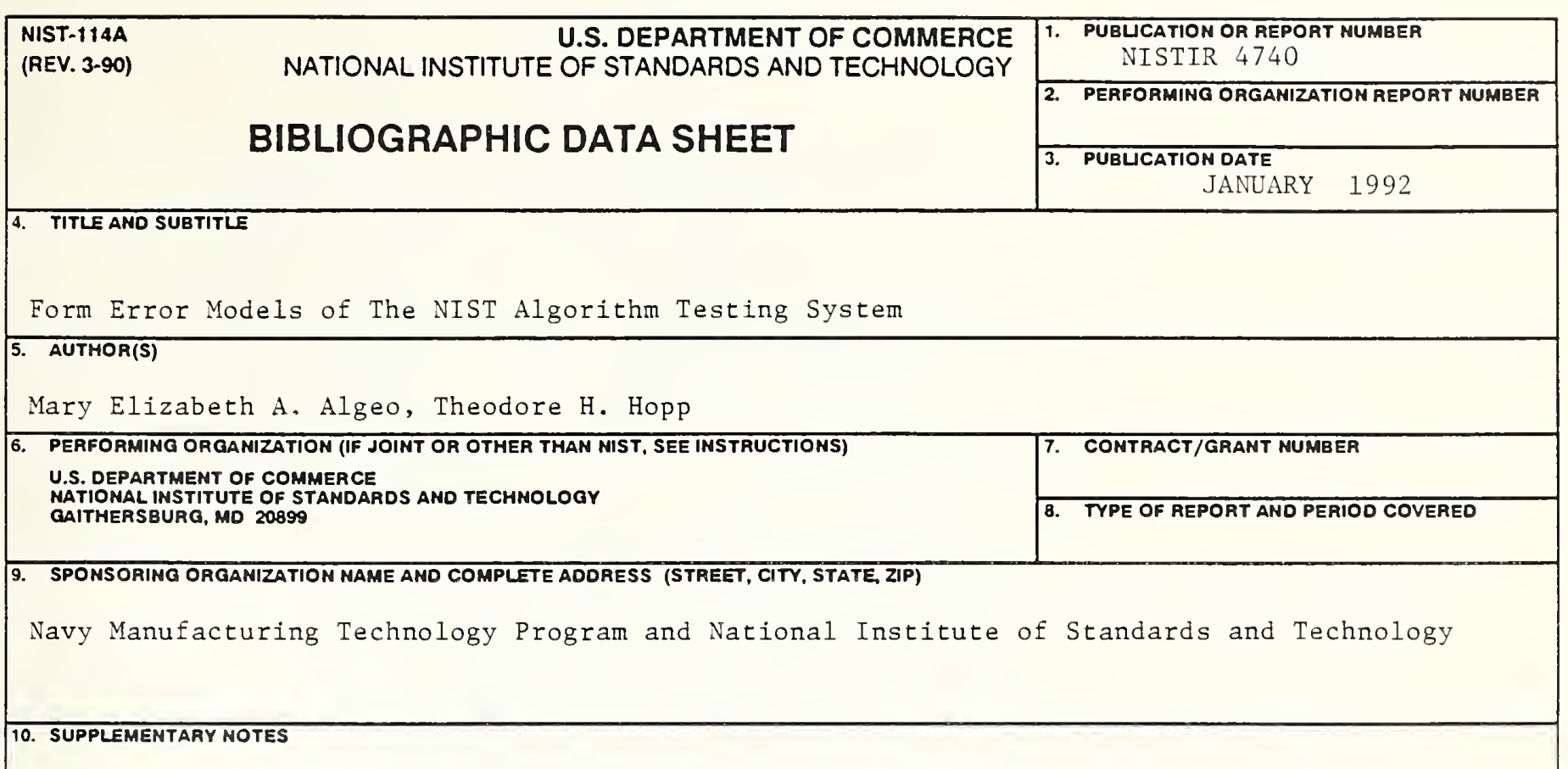

11. ABSTRACT (A 200-WORD OR LESS FACTUAL SUMMARY OF MOST SIGNIFICANT INFORMATION. IF DOCUMENT INCLUDES A SIGNIFICANT BIBUOGRAPHY OA UTERATURE SURVEY, MENTION IT MERE.)

The NIST Algorithm Testing System is a software package for testing geometric fitting software. In order to create realistic test scenarios, the ATS provides the capability to generate test data that simulate part features with form errors. This report documents the form error models used in the Algorithm Testing System.

12. KEY WORDS (6 TO 12 ENTRIES; ALPHABETICAL ORDER; CAPITAUZE ONLY PROPER NAMES; AND SEPARATE KEY WORDS BY SEMICOLONS)

algorithm testing; data generation; form errors; geometry modeling; manufacturing errors; metrology software; NIST Algorithm Testing System; software testing

\begin{tabular}{|c|c|c|}
\hline \multicolumn{2}{|c|}{ 13. AVAILABILTY } & \multirow{2}{*}{$\begin{array}{l}\text { 14. NUMBER OF PAINTED PAGES } \\
12\end{array}$} \\
\hline$X$ & UNLUMITED & \\
\hline & $\begin{array}{l}\text { ORDER FROM SUPERINTENDENT OF DOCUMENTS, U.S. GOVERNMENT PRIMTIMG OFFICE, } \\
\text { WASHINGTON, DC } 20402 \text {. }\end{array}$ & 15. PRICE \\
\hline $\mathrm{X}$ & ORDER FROM NATIONAL TECHMICAL INFORMATION SERVICE (NTIS), SPRINGFIELD, VA 22161. & \\
\hline
\end{tabular}




